\title{
Characterization of Corrosion Interfaces by the Scanning Kelvin Probe Force Microscopy Technique
}

\author{
V. Guillaumin,* P. Schmutz, ${ }^{*}$ and G. S. Frankel*,z \\ Fontana Corrosion Center, Department of Materials Science and Engineering, The Ohio State University, \\ Columbus, Ohio 43210, USA
}

\begin{abstract}
A variety of interfaces relevant to corrosion processes were examined by the scanning Kelvin probe force microscopy (SKPFM) technique in order to study the influences of various parameters on the measured potential. SKPFM measurements performed on AA2024-T3 after solution exposure showed that surface composition is not the only parameter that controls the Volta potential difference, which is measured by SKPFM. The influence of surface oxide structure and adsorption at the oxide surface can be probed by SKPFM and lateral potential gradients can be observed in the absence of significant differences in oxide composition. The influence of tip-sample separation distance on the measured Volta potential difference was studied for different pure oxidecovered metals. SKPFM measurements were made in air on pure $\mathrm{Ni}$ and Pt samples withdrawn from solution at open circuit or under potential control. The Volta potential difference was found to be composed of a transient component that slowly discharged and a more permanent component associated with the charge of adsorbed species. The Volta potential difference transients measured on the samples emersed under potential control decayed much slower than the open-circuit potential transient measured in solution upon release of the potential control. These different measurements validate the use of SKPFM for the prediction of local corrosion sites and the study of surface modification during solution exposure.

(c) 2001 The Electrochemical Society. [DOI: 10.1149/1.1359199] All rights reserved.
\end{abstract}

Manuscript submitted February 14, 2000; revised manuscript received December 18, 2000.

Scanning Kelvin probe force microscopy (SKPFM) is a powerful technique to characterize the corrosion processes associated with local inhomogeneities on passive surfaces. ${ }^{1-4}$ The topography and potential distribution of a surface can be simultaneously mapped with submicrometers sensitivity by this technique. It is a scanning probe microscopy (SPM) method that is a modification of atomic force microscopy (AFM) and associated techniques. This technique senses the electrostatic field near an interface using a different approach than that of a standard Kelvin probe. Also, the probe tip operates at a much closer distance from the surface, which enables the enhanced spatial resolution relative to a standard Kelvin probe. SKPFM was developed and first used to study photoresist-covered Si wafers ${ }^{5}$ and semiconductor dopant profiles. $^{6}$ This technique is quite new ${ }^{7-12}$ and the number of investigations using it has increased in the past two years. ${ }^{13-16}$ The ability to map the potential on a submicrometers scale is extremely useful in studies of localized corrosion of certain $\mathrm{Al}$ alloys, which contain heterogeneities on that scale and larger. ${ }^{1-4}$ Furthermore, it may be considered that the distribution of potential across a surface is even more relevant to the corrosion process than surface composition, which can be determined by a range of surface analytical techniques.

The classical Kelvin probe technique has been used for some time to measure the potentials of various metal surfaces by nulling the current flowing between the sample and a closely positioned vibrating probe that is electrically connected. ${ }^{17}$ In 1979 , Hoelzl and Schulte published a compilation of the work functions in vacuum determined by the Kelvin probe technique for most of the common pure elements and listed the effects of adsorption processes. ${ }^{18}$ The influences of internal stresses and temperature on the work function were also discussed. More recent studies have investigated model electrochemical interfaces in vacuum. ${ }^{19-21}$ Stratmann et al. have demonstrated the principle $e^{22,23}$ and the utility of the Kelvin probe technique in corrosion studies of iron ${ }^{24,25}$ and aluminum. ${ }^{26}$ They measured the Volta potential difference of samples covered with a thin layer of electrolyte using a probe that did not touch the electrolyte. The Volta potential difference was shown to vary linearly with the corrosion potential of the sample/solution interface determined with a standard reference electrode positioned in the electrolyte layer. $^{23,24}$ With this technique, it is also possible to measure the corrosion potential under an organic coating, which provides infor-

\footnotetext{
* Electrochemical Society Active Member.

z E-mail: frankel.10@osu.edu
}

mation on defects at the metal-coating interface. ${ }^{27-30}$ Standard scanning Kelvin probes have a lateral resolution for potential measurement of around $100 \mu \mathrm{m} .^{23}$

The advantage of the SKPFM lies in its enhanced lateral detection limit, which was shown ${ }^{2}$ to be at least $0.1 \mu \mathrm{m}$. In previous papers, ${ }^{1-4,31}$ SKPFM was used to study the reactivity of the coarse intermetallic particles in AA2024-T3. Topographic maps indicated that the intermetallic particles might or might not protrude from the surface of a freshly polished sample, depending on the effects of differential polishing rates and dissolution reactions during polishing. The potential distribution from SKPFM provided a much clearer indication of the location of the intermetallic particles on a polished surface. ${ }^{1,2}$ Before any solution exposure, all intermetallic particles, including the $\mathrm{Al}-\mathrm{Cu}-\mathrm{Mg}$-containing $\mathrm{S}$ phase particles, had a potential noble to that of the matrix. The technique allowed careful examination of the evolution of the potential and topography after solution exposure. The potential measured on a number of pure metal samples after exposure to deionized (DI) water or $0.5 \mathrm{M} \mathrm{NaCl}$ was found to be linearly related to the open-circuit potential measured in solution before the samples were removed. ${ }^{2}$ Based on this observation, it was suggested that the potential measurement made by SKPFM provides an indication of the nobility of each particle relative to the matrix, which is important in determining their role in galvanic interactions. ${ }^{2}$ Despite this correlation and the fact that the technique is very useful to characterize defects on sample surfaces, questions exist regarding the nature of the potential measured by SKPFM, and the limitations of measurements made in air for understanding phenomena taking place in solution.

Hansen et al. studied the interfacial region using emersed electrodes, which were removed from the electrolyte under controlled applied potential. ${ }^{32-37}$ It was demonstrated by conductance, ${ }^{32,33}$ reflectance, ${ }^{34}$ and resistance ${ }^{35}$ measurements that the double layer formed at an electrode/electrolyte interface can be preserved upon emersion from solution. The work function of emersed electrodes was also studied using a Kelvin probe. ${ }^{38-40}$

The present study attempts to enhance the understanding of the nature of the potential measured by the SKPFM. In theory, for the simplest case of a metal-solution interface, the absolute potential difference or Galvani potential difference across an electrified interface can be conceptually separated in two components ${ }^{41,42}$ : the outer potential difference, sometimes called the Volta potential difference $\left({ }^{\mathrm{M}} \Delta^{\mathrm{S}} \Psi\right)$, and the dipole potential difference $\left({ }^{\mathrm{M}} \Delta^{\mathrm{S}} \chi\right)$. The outer potential difference is related to the free charge distribution at the electrode surface. It corresponds to a long-range coulomb potential difference and depends on the distance from the metal surface. The 
dipole potential difference is related to the oriented dipoles in the interphase region. The arrangement of oriented dipoles is equivalent to a charge separation. Therefore, a potential difference that can only be detected close to the surface occurs across the dipole layer.

Charge distribution can be described in different ways depending on the nature of the interface considered. In the case of a passive surface, where a thin oxide covers the surface, the interface might preferably be described as a semiconductor-liquid interface. ${ }^{43}$ The charge distribution in the solid is then separated in a space charge, which characterizes the electron or hole distribution within the semiconductor (extending into the bulk), and surface states in a compact layer $(\sim 0.5 \mathrm{~nm})$ at the surface. The solution double-layer component is then described in a similar fashion to a metal-liquid interface. Depending on the surface-state density, the potential at the interface can be completely related to space charge (band-edge level pinning) or to the surface state (Fermi level pinning). ${ }^{43}$ In most cases, an intermediate situation is present. However, this formalism, developed for bulk semiconductors, is very theoretical and poorly defined for a thin defective oxide. In the case of a pure metal, the space charge is located directly at the interface and cannot be distinguished from the compact layer. The Volta potential has not been defined for a semiconductor-electrolyte interface, but the concept can be adapted to this type of interface since it is related to the charge distribution on the surface, and the semiconducting properties of nanometer-thick oxide are anyway difficult to assess. The major difference with respect to a metal-electrolyte interface is the reduced freedom of the electrons resulting in a larger depth distribution of the charges.

Another approach to the description of an interface can be found in physics. Physicists have defined the absolute work function of an electrode for a metal-vacuum interface as the critical energy required to remove an electron from the metal into the vacuum. ${ }^{18}$ However, although this formalism is sometimes used to describe metal-electrolyte interfaces, the meaning of the term "work function" is less clear in this case, and the presence of an oxide on the electrode surface as described above complicates the situation further. The absolute work function of an electrode has been defined as the energy required to remove an electrode from deep inside the metal to a point just outside its surface such that the electron no longer feels its image charge. ${ }^{44}$ Details of the interface structure are ignored and cannot be added to the formalism easily. The work function is dependent on multiple parameters, such as charge in the oxide and structure of the double layer, so that work function measurements allow detection of any change of the electric double layer when the sample is removed from an electrolyte, as in the case of an emersed electrode. In summary, the meaning of a work function or Volta potential for a passive metal/electrolyte interface is unclear and the terms "modified" or "electrochemical" work function are used to distinguish between vacuum and in-solution measurements that represent two completely different situations. A single formalism is required, and it is assumed in this work that the Volta potential difference of such a system is related to the free and trapped charge at the surface.

Experimental investigation of the molecular and electronic properties of the metal-solution interface is complex and challenging. Kizhakevariam et al. ${ }^{19}$ characterized model electrochemical interfaces in ultrahigh vacuum. The influence of various solvents on the interfacial potential profile on $\mathrm{Pt}(111)$ was investigated by these authors by work-function measurements and infrared Stark effects with the primary objective of assessing the role of surface solvation in related electrochemical systems. Solvent adsorption onto clean $\operatorname{Pt}(111)$ was found to result in substantial decreases in work function. The solvent molecules in the first one to two monolayers provided the predominant contribution to the overall surface potential drop. Considering this concept for the oxide-air interfaces, the Volta potential difference measured by the SKPFM might also be determined by the electric contribution of the first monolayers present at the electrode surface.

The SKPFM technique allows potential measurements at a very small distance from the surface; a tip-sample separation of $100 \mathrm{~nm}$ is typically used. Textbook descriptions indicate that measured Volta potentials are constant over a wide distance range (from 100 $\mathrm{nm}$ to a few micrometers away from the surface), but should drop off for measurements made at distances less than about $100 \mathrm{~nm}$ owing to the effects of image or dipole charges close to the surface electrode. ${ }^{41,42}$ Indeed, the potential measured by SKPFM does not vary for tip/surface distances from $100 \mathrm{~nm}$ to a few micrometers. It is our belief that the potential measured by this technique is strongly related to the Volta potential difference, the distance of $100 \mathrm{~nm}$ to a few micrometers being in the constant potential region. Since the SKPFM technique is fundamentally different than the standard Kelvin probe method, it is invalid to assume that the measured signal is identical and behaves similarly. The goal of this work is to probe the meaning and behavior of the potential measured by SKPFM.

\section{Experimental}

SKPFM was performed with a commercial AFM (Nanoscope IIIa, Digital Instruments). This instrument can measure the surface topography and potential distribution simultaneously on a line-byline basis using metal-coated silicon cantilevers that are electrically conducting. The cantilevers were also obtained from Digital Instruments. Cantilevers with three different metal coatings were used: Co-40Cr, Ni-Si, or Pt-Ir. The principle and details of the SKPFM measurement have been previously described. ${ }^{2}$ In short, it involves applying an ac voltage to a tip, which stimulates oscillations of the cantilever in the presence of an electric field, and then nulling the oscillations by adding a dc voltage that balances the field. This approach to potential distribution measurement is not possible in an aqueous solution because the large voltages applied to the tip would result in faradaic reactions. In this study, all potential mapping was performed in air. Since this technique is a nulling method, the output signal from the instrument was inverted; it has been shown previously that inversion of the signal is needed to obtain the expected polarity of the potential measurements. ${ }^{2}$ The values obtained are relative to the potential of the tip. The tips are only pseudoreferences, since their potential may vary with changes in the surface oxide. In order to avoid errors associated with variations in the tips or instabilities in the instrument electronics, the potential measurements were calibrated by comparison to the potential measured on a pure $\mathrm{Ni}$ surface after immersion in $\mathrm{DI} \mathrm{H}_{2} \mathrm{O}$. Ni was chosen as a reference because it was found to have a stable potential. All potential measurements are reported herein relative to that of a $\mathrm{Ni}$ sample. Consecutive measurements in air on a stable reference sample using different tips coated with the same metal showed potential difference of less than $50 \mathrm{mV}$, giving an indication of the reproducibility of this method.

Potential measurements of emersed samples were performed on pure metal samples. The influence of the tip-sample distance on the measured potential was studied using pure $\mathrm{Al}, \mathrm{Ni}$, and Fe electrodes. The samples were polished through 1200 grit $\mathrm{SiC}$ paper in water and ultrasonically cleaned in distilled water. They were immersed for 30 min in distilled water at open circuit, air dried, and placed in the SKPFM.

Potential measurements of samples emersed from $0.1 \mathrm{M} \mathrm{Na}_{2} \mathrm{SO}_{4}$ under potential control were also performed. Pure Pt and Ni samples were studied in order to compare two different types of surface oxides. For each experiment, two identical working electrodes were electrically coupled. The open-circuit potential (OCP) in solution was first monitored for $60 \mathrm{~s}$. The two coupled electrodes were then polarized for $3 \mathrm{~min}$ at a cathodic potential approximately $1000 \mathrm{mV}$ lower than the OCP. In order to control the applied potential during the emersion process, only the test electrode was removed while the other electrode was kept immersed under applied potential. The emersed electrode was quickly rinsed with DI water, dried, and mounted in the SKPFM to measure the Volta potential difference decay with time. Potential control of the second electrode was then released, and the OCP transient was monitored for $10 \mathrm{~min}$. For 
comparison, the Volta potential difference was also measured for electrodes immersed at open circuit for $30 \mathrm{~min}$ in DI water or in $0.1 \mathrm{M} \mathrm{Na}_{2} \mathrm{SO}_{4}$.

AA2024-T3 samples were also examined in situ in chloridedichromate-containing solution with the Digital Instruments fluid cell using contact-mode AFM and a silicon tip. The tip was rastered in situ at high applied forces across the samples for varying periods of time. The samples were then removed from solution, rinsed, dried, and re-examined in air to generate topography and Volta potential difference maps. More details of the approach were given previously. ${ }^{1,4}$ Before the scratching experiment, the AA2024-T3 (nominal composition $4.9-3.8 \% \mathrm{Cu}, 1.8-1.2 \% \mathrm{Mg}, 0.9-0.3 \% \mathrm{Mn}$, $0.5 \% \mathrm{Fe}$ and $\mathrm{Si}, 0.25 \% \mathrm{Zn}, 0.1 \% \mathrm{Cr}, 0.05 \mathrm{Ti}$, balance $\mathrm{Al}$ ) samples were mechanically polished in ethanol (with no exposure to water) to 1200 grit $\mathrm{SiC}$ paper and then with $1 \mu \mathrm{m}$ diamond paste in a nonaqueous slurry (Blue Lube from Struer) to minimize corrosion. Finally, they were rinsed with ethanol.

A PHI-Perkin/Elmer 680 scanning Auger nanoprobe system equipped with a field emission electron gun was used for surface analysis. A $10 \mathrm{kV}, 10 \mathrm{nA}$ electron-beam was used for all the measurements. Composition of the surface can be obtained with a lateral resolution of about $30 \mathrm{~nm}$ for these beam parameters. On AA2024-T3 samples, depth profiling was performed by sputtering a $2 \times 2 \mathrm{~mm}$ area with $1 \mathrm{kV}$ Ar ions at a current of $0.5 \mu \mathrm{A}$. The sputtering rate was always calibrated with respect to a $100 \mathrm{~nm} \mathrm{SiO}_{2} / \mathrm{Si}$ reference sample. For the given conditions, it was around $3 \mathrm{~nm} / \mathrm{min}$. A higher sputtering rate of around $80 \mathrm{~nm} / \mathrm{min}$ $\left(5 \mathrm{kV} \mathrm{Ar}^{+}\right.$ions at $\left.1 \mu \mathrm{A}\right)$ was used to reveal the microstructure on pure magnesium.

\section{Results and Discussion}

SKPFM characterization of the intermetallic particles of AA2024-T3.- It is well known that two types of coarse intermetallic particles can be distinguished in AA2024: more or less spherical $\mathrm{Al}-\mathrm{Cu}-\mathrm{Mg}$-containing particles, which can be assigned to the $\mathrm{Al}_{2} \mathrm{CuMg}$ chemical type or $\mathrm{S}$ phase, and very large, irregularly shaped $\mathrm{Al}-\mathrm{Cu}-\mathrm{Mn}-\mathrm{Fe}-$ containing particles. ${ }^{45-47}$ Volta potential difference maps of these types of particles have been given previously. ${ }^{1,2}$ In this study, the depth distribution of the Volta potential difference was examined.

Figures $1 \mathrm{a}$ and $\mathrm{b}$ show the topography and potential distribution obtained simultaneously on a sample of an as-polished sample of AA2024-T3 in air. A region protruding slightly from the surface is barely visible in the center of the topography map. Generally, Al$\mathrm{Cu}-\mathrm{Mn}-\mathrm{Fe}$ intermetallic particles protrude from polished AA2024-T3 surfaces because of their higher hardness and consequential lower rate of polishing relative to the matrix. Furthermore, unlike $\mathrm{Al}-\mathrm{Cu}-\mathrm{Mg}$ particles, they are relatively nonreactive and do not corrode during polishing. A scanning electron microscopy (SEM) image of the same area is shown in Fig. 1c. The intermetallic particles in AA2024-T3 exhibit a contrast in secondary electron intensity because their high $\mathrm{Cu}$ content results in a higher electron scattering relative to the matrix. The secondary electron intensity observed is a combination of this effect and any surface topography resulting from differential polishing or dissolution during polishing. Energy-dispersive spectroscopy (EDS) analysis of these secondphase particles allowed the two types of intermetallics to be distinguished. The particles labeled 1-3 (including the large central particle) were $\mathrm{Al}-\mathrm{Cu}-(\mathrm{Fe}, \mathrm{Mn})$ intermetallics, and the particles labeled $\mathrm{A}-\mathrm{D}$ were $\mathrm{Al}-\mathrm{Cu}-\mathrm{Mg}$-containing intermetallics. All of the intermetallic particles seen in the SEM image are very easily distinguished in the Volta potential difference map shown in Fig. 1b. The potential of the Al-Cu-Mg particles was slightly lower than the that of $\mathrm{Al}-\mathrm{Cu}-$ $(\mathrm{Fe}, \mathrm{Mn})$ particles but higher than that of the matrix. This is an example of the power of the SKPFM technique for locating the intermetallic particles and even, to a certain extent, for identifying the type of particle with an AFM.
Auger electron spectroscopy (AES) analysis of the as-polished sample showed that the oxide film composition was not the same on the different particles and the $\mathrm{Al}$ matrix. ${ }^{48}$ Indeed, the oxide present on the $\mathrm{Al}-\mathrm{Cu}-\mathrm{Mg}$ particles contained $\mathrm{Mg}$ and a small amount of $\mathrm{Cu}$, whereas the oxide present on the $\mathrm{Al}-\mathrm{Cu}-(\mathrm{Fe}, \mathrm{Mn})$ particles contained $\mathrm{Cu}$ and $\mathrm{Fe}$. The oxide on the $\mathrm{Al}$ matrix film was obviously aluminum oxide.

The sample in Fig. 1a-c was then $\mathrm{Ar}^{+}$sputter etched to remove 2-3 nm of the surface, and then re-exposed to air. SKPFM was used to map the Volta potential difference of the same area, Fig. 1d. The Mg-containing particles are dark in Fig. 1d, which indicates that their potential was lower than that of both the (Fe, Mn)-containing intermetallics and the matrix. In contrast to the behavior of the $\mathrm{S}$-phase particles, the potential at the $\mathrm{Al}-\mathrm{Cu}-(\mathrm{Fe}, \mathrm{Mn})$ particle remained higher than the matrix. This decrease in the Volta potential difference of the S-phase particles can be explained by changes in surface adsorption, oxide composition, or oxide structure. It is possible that this decrease was the result of a modification of the surface associated with the sputtering process. However, the entire surface was sputtered and only the potential on the S-phase particles changed. Therefore, the change in the behavior of the S-phase particles seems to be associated with a through-thickness gradient in properties. AES analysis performed simultaneously to the sputtering indicated that the sputter-etching did not completely remove the oxide film, which was determined to be approximately 5-6 nm thick for the as-polished sample. Actually, the lower Volta potential is in good agreement with the high reactivity of the S-phase particles. Furthermore, it was shown previously that the initially high potential of the Mg-containing particles in AA2024-T3 decreased relative to the matrix during open-circuit exposure to a chloride solution. ${ }^{1}$ When the potential decreased to that of the surrounding matrix, localized corrosion initiated at the particles. The effect of sputter etching on the Volta potential difference of the Mg-containing particles is therefore similar to that of open-circuit exposure to a chloride solution.

Potential measurement performed by SKPFM allows investigation and prediction of the influence of surface treatment on the corrosion susceptibility. The composition of the oxide film on the different particles and the matrix did not change as a result of the sputter etching, within the resolution of AES. The particle potential contrast and the initiation of the corrosion process are clearly not related only to the oxide film composition. No characterization techniques exist to measure, with high lateral resolution, changes that might occur in the electronic structure of the surface. These SKPFM results demonstrate the complex behavior of these surface oxides and the importance of the potential distribution measurement for a further understanding of corrosion behavior.

SKPFM characterization of AA2024-T3 after exposure to a dichromate-containing solution.-Corrosion inhibition is often the result of subtle changes in the surface oxide structure that are beyond standard surface characterization methods. One example where inhibitor ions interact with the surface is immersion in chloride solution containing dichromate ions. Chromates are extremely effective and widely used as corrosion inhibitors for high-strength $\mathrm{Al}$ alloys in aerospace applications. The behavior of pure $\mathrm{Al}$ and AA2024-T3 during AFM scratching in chloride-dichromate solutions has been discussed. ${ }^{3,4,31}$ The images in Fig. 2 and 3 have been presented and discussed previously; ${ }^{3,4,31}$ a summary of the observations relevant to further characterization are given.

The topography and potential maps of the as-polished AA2024-T3 sample are shown in Fig. 2a and b, respectively. The central portion of the area in Fig. $2 \mathrm{a}$ and $\mathrm{b}$ was then scratched at open circuit in $0.5 \mathrm{M} \mathrm{NaCl}+10^{-4} \mathrm{M} \mathrm{Na}_{2} \mathrm{Cr}_{2} \mathrm{O}_{7}$ for $6 \mathrm{~h}$ with a $\mathrm{Si}$ AFM tip at a force set point of $0.5 \mathrm{~V}$. The resulting topography and potential maps (measured in air) are shown in Fig. 2c and d. Two pits developed in the Al matrix in the top right, and a cell-like, high-potential structure developed in the potential map, Fig. 2d. It is interesting to note that, on the one hand, there is no visible topo- 

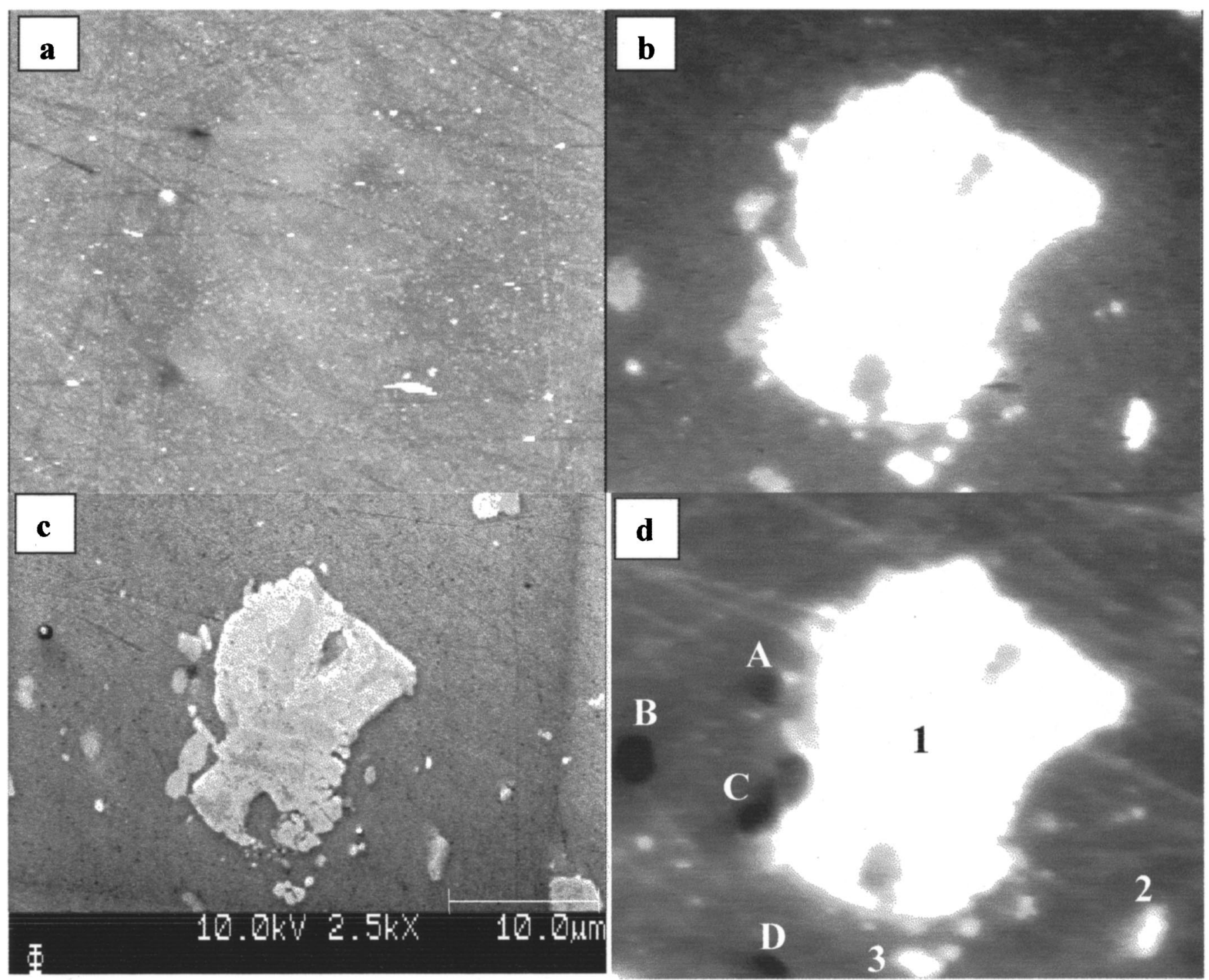

Figure 1. Region in AA2024-T3. (a) $30 \times 30 \mu \mathrm{m}$ AFM topographic image of as-polished sample with a gray scale range of $200 \mathrm{~nm}$. (b) Volta potential difference distribution of the same area with a gray scale range of $0.5 \mathrm{~V}$. (c) SEM image of the same area. Particles 1-3 are Al-Cu-(Fe, Mn) particles and A-D are $\mathrm{Al}-\mathrm{Cu}-\mathrm{Mg}$ particles. (d) Volta potential difference distribution of the same region with a gray scale range of $0.5 \mathrm{~V}$ after removal of $2-3 \mathrm{~nm}$ by sputter etching.

graphic feature in Fig. 2c that could justify the potential structure, and on the other hand, the debris line and corrosion products seen on the edges of the scratched area in the topographic map do not exhibit potential contrast. It should also be noted that the S-phase particles remained intact during the scratching experiment. No pit can be observed at their location on the topography map, and the slight contrast observed on the final potential distribution map attests to their presence. Figure 3 is an SEM image of the same area shown in Fig. 2 after AFM scratching. The pits that developed in the matrix can be observed. In the SEM image of Fig. 3, apparent cracks are visible near particle 2 as well as between particle 3 and the large pit at the bottom of the image. These cracks correspond to the position of part of the high-potential structure. However, the rest of the highpotential structure cannot be seen in the SEM image. It is also interesting to note that the apparent cracks seen in the SEM image are not observed in the AFM topography map shown in Fig. 2c. These cracks might correspond to an early stage of intergranular or subgrain boundary attack, which could be filled or covered with corrosion products so that they are not observed at the surface. Secondary electron emission can vary for multiple reasons and interpreting
SEM contrast as topographic features might be erroneous. Nonetheless, SEM observations are clearly insufficient to fully characterize the surface structure in this case.

Auger analyses were performed on various spots on the surface to check whether differences in the oxide film composition could explain the presence of the high-potential structure seen in Fig. 2d. In summary, the concentration in the oxide of elements contained in the alloy do not change (within the resolution of AES) as a result of the scratching experiment for any area on the surface, including the intermetallics and the matrix. However, lateral differences in $\mathrm{Cr}$ concentration were observed after the AFM scratching treatment. Specific attention was given to the $\mathrm{Cr}$ distribution as determined by the LMM Auger transition peak.

The Auger spectra are shown in Fig. 4 for regions labeled in the SEM image in Fig. 3. Note that this labeling scheme is different than that used in Fig. 2. A Cr peak was found in every analyzed area (all of the different intermetallic particles and on the matrix both in and outside the scratched area), which indicates that the surface was fully covered with a thin Cr-enriched layer. The Cr LMM transition was superimposed on the high-energy shoulder of the larger oxygen 

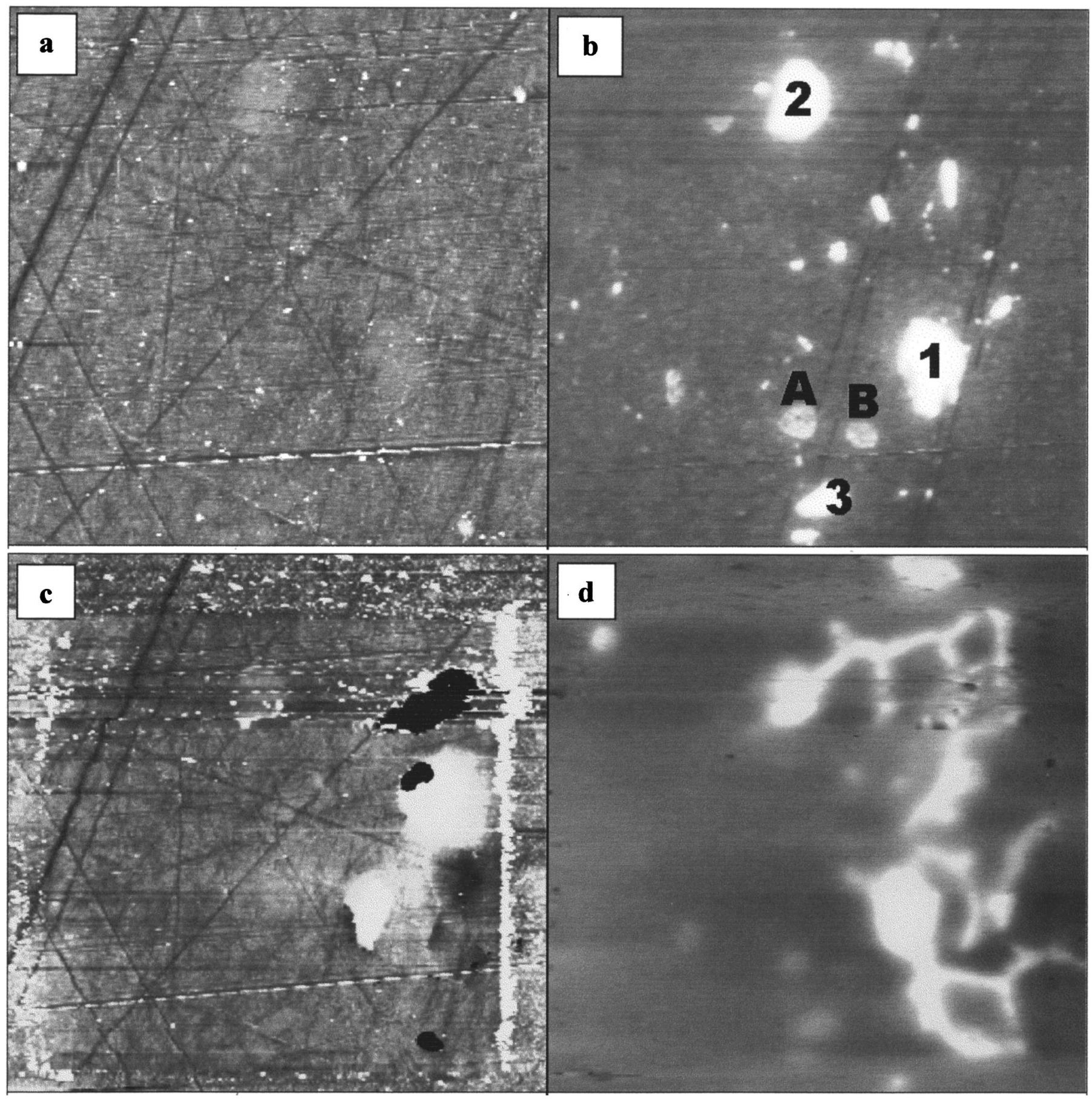

Figure 2. AFM images of an AA2024-T3 alloy surface. (a) $50 \times 50 \mu \mathrm{m}$ topographic image of as-polished sample, with a gray scale range of $200 \mathrm{~nm}$. (b) Volta potential difference distribution of the same area, with a gray scale range of $0.5 \mathrm{~V}$. Particles 1-3 are $\mathrm{Al}-\mathrm{Cu}-(\mathrm{Fe}, \mathrm{Mn})$ particles, and A-B are Al-Cu-Mg particles. (c) Topographic image after scratching the central region at $0.5 \mathrm{~V}$ set point in $0.5 \mathrm{M} \mathrm{NaCl}+10^{-4} \mathrm{M} \mathrm{Na}_{2} \mathrm{Cr}_{2} \mathrm{O}_{7}$ for $6 \mathrm{~h}$ in the AFM, with a gray scale range of $200 \mathrm{~nm}$. (d) Volta potential difference map of same area after scratching, with a gray scale range of $0.5 \mathrm{~V}$. These images have been previously published. ${ }^{3,4}$

KLL transition. So, to prevent artifacts, the data are represented in Fig. 4 as direct energy spectra instead of the more standard differentiated format. The inelastic background was different on the different parts of the alloy and was subtracted from the spectra to facilitate comparison of the Cr LMM intensities. The background from the $\mathrm{O}$ peak tail was relatively similar in these cases, so direct comparison is possible without further removal of the Gaussian tail of the O KLL transition. A slightly larger amount of $\mathrm{Cr}$ was deposited on the $\mathrm{Al}-\mathrm{Cu}-\mathrm{Mg}$ particles compared to the $\mathrm{Al}$ matrix and the $\mathrm{Al}-\mathrm{Cu}-(\mathrm{Fe}, \mathrm{Mn})$ particles, Fig. 4a. This indicates that the reactivity of this type of particle toward chromate ions was higher in the chloride+dilute chromate solution. The small concentration of dichromate in solution $\left(10^{-4} \mathrm{M}\right)$ greatly enhanced the corrosion resistance of this phase, which dissolves very quickly during scratching in dichromate-free chloride solutions. The same amount of magnesium was found in the oxide before and after the scratching experiment. Consequently, addition of dichromate prevented magnesium dealloying. Moreover, after the scratching experiment, the $\mathrm{Al}-\mathrm{Cu}-\mathrm{Mg}$ particles had almost the same potential as the matrix, Fig. 


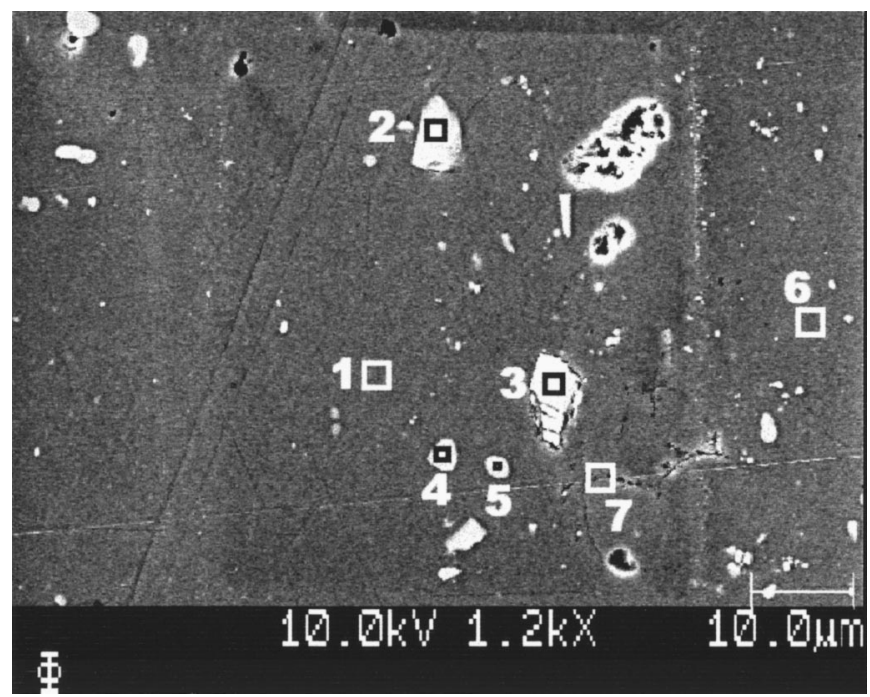

Figure 3. SEM image corresponding to the AFM analysis presented in Fig. 2. The numbers indicate the regions analyzed by AES and described in Fig. 4. Note that even though this image is of the same area as shown in Fig. 2, the labeling of the features and regions in the area is different. This image has been previously published. ${ }^{3,4}$

$2 \mathrm{~d}$. So, in this case although the oxide film present on the $\mathrm{Al}-\mathrm{Cu}-\mathrm{Mg}$ particles contained a higher amount of $\mathrm{Cr}$ compared to both the $\mathrm{Al}-\mathrm{Cu}-(\mathrm{Fe}, \mathrm{Mn})$ particles and the $\mathrm{Al}$ matrix, the potential is almost identical, indicating, as previously mentioned, that potential and surface composition are unrelated.

Figure $4 \mathrm{~b}$ shows the $\mathrm{Cr}$ LMM peaks from three different matrix areas: a low-potential region (area 1), a high-potential region (area 7), and an unrastered region (area 6). The amount of $\mathrm{Cr}$ on the surface was essentially the same on the three areas. Considering all the elements present, the composition of the oxide was identical (within the resolution of AES) on these areas, and the Volta potential difference contrast shown in Fig. 2 cannot be explained by compositional variations.

A graph was published in a previous paper showing a linear relation between the Volta potential difference of pure elements measured in air and their corrosion potential in different aqueous solution. $^{2}$ This correlation indicates that this potential is a useful and meaningful measurement of the practical nobility of a surface in the same way that lists of corrosion potentials of real materials in different environments, like seawater, have used for years. However, to summarize the observations described here, large potential differences were observed on areas in the AA2024-T3 matrix after scratching in the chloride/dichromate solution with no detectable difference in surface composition. Furthermore, the $\mathrm{Al}-\mathrm{Cu}-\mathrm{Mg}$ particles did not exhibit a large potential contrast with respect to the matrix, even though they had a measurable difference in surface composition (a higher amount of chromium in the oxide film). This means that the potential measurements made with the SKPFM are not simply related to the composition of the oxide film at a level that can be discerned by Auger analyses. Nonetheless, these potential measurements are apparently useful predictors of corrosion behavior, as evidenced by the rapid dissolution of S-phase particles in chloride solution when their Volta potential decreased to that of the matrix. ${ }^{2}$

In order to avoid the complications associated with local heterogeneities, further studies into the nature of the Volta potential difference measured by SKPFM were made on pure metal samples.

SKPFM characterization of pure magnesium.-The behavior of $\mathrm{Mg}$ is of interest since it is one of the major components of the deleterious S-phase particles in AA2024-T3. It is well known ${ }^{46,47}$ that the dissolution of these inclusions in chloride-containing solu-

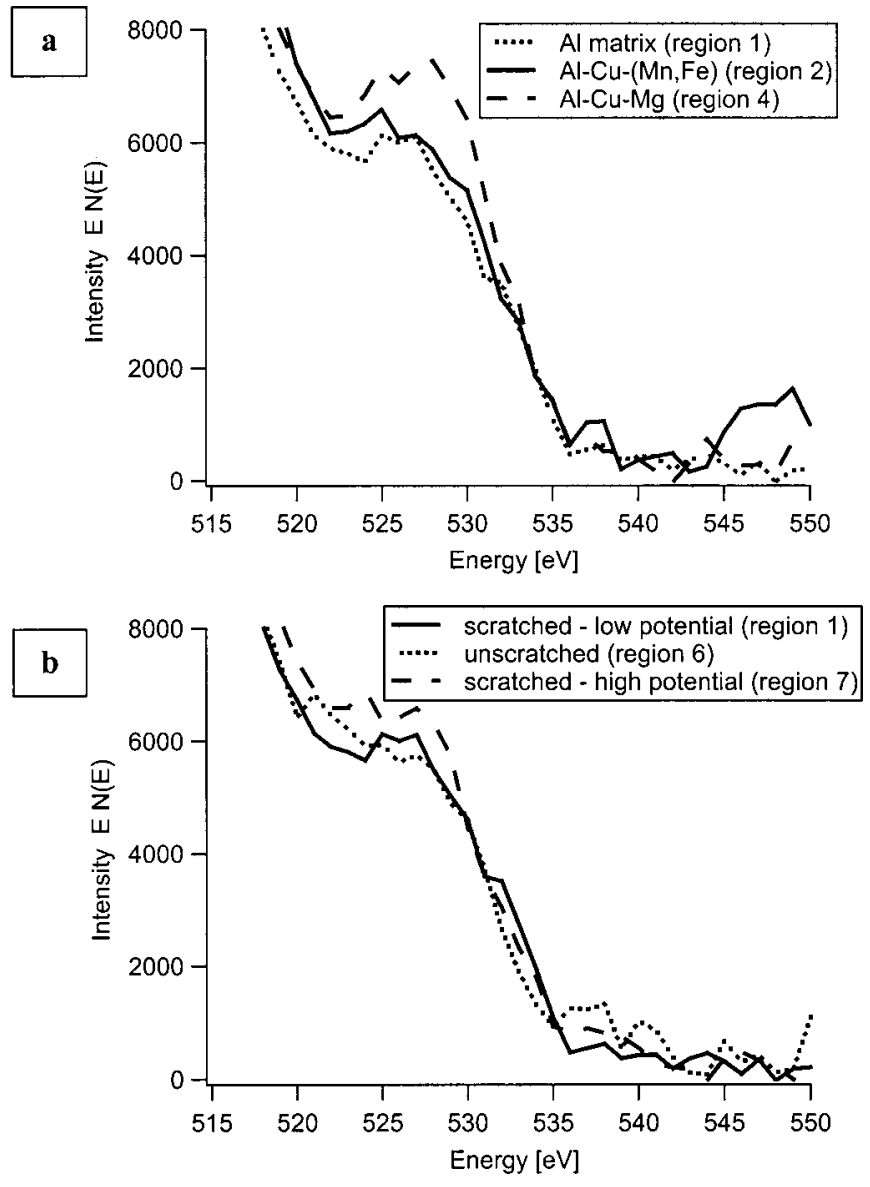

Figure 4. Cr LMM peak $\left(E_{\text {kin }}=525 \mathrm{eV}\right)$ corresponding to the analyzed regions shown in Fig. 3: (a) Al matrix and different intermetallic particles in the rastered area and (b) Al matrix areas: high- and low-potential rastered areas (see Fig. 2 and 3) and outside the rastered area.

tions involves severe dealloying of $\mathrm{Mg}$, resulting in the formation of $\mathrm{Cu}$-rich remnants that are harmful to the corrosion resistance of the alloy. Therefore, the higher corrosion resistance of the $\mathrm{Al}_{2} \mathrm{CuMg}$ particles in chloride solutions containing dilute dichromate is likely due to a strong interaction between the magnesium and the dichromate ions. Specific attention was given to the corrosion behavior of pure magnesium in chloride-dichromate-containing solution, and the results obtained will be presented elsewhere. ${ }^{49}$

Figure 5 presents two scanning electron micrographs of a pure magnesium surface after polishing and then $\mathrm{Ar}^{+}$sputter etching. 7 $\mu \mathrm{m}$ of the surface were removed by the sputtering process, revealing the microstructure of the material. Both grains and grain boundaries are clearly visible on the micrographs, as well as defects inside the grains. The defects are either low-angle boundaries, slip planes, or twins. The hexagonal crystal structure of magnesium limits the amount of deformation that it can tolerate. At room temperature, deformation occurs mainly by slip on the basal planes in the closepacked $\langle 11 \overline{2} 0\rangle$ direction, and by twinning on the pyramidal $\{10 \overline{1} 2\}$ planes. ${ }^{50}$

Figure 6 shows topography and potential maps of the region of the sample presented in Fig. 5b. Figures $6 \mathrm{a}$ and $\mathrm{c}$ are 2D and 3D topography maps, respectively. It is particularly visible on the 3D topography that some grains are sputter etched faster than others. Since the Mg sample is very pure, this variation in sputter rate is likely due to a difference in the crystallographic orientation of the grains. It is also interesting to note that some grains are not uniformly sputter etched, resulting in a substantial roughness of the surface. The defects inside the grains are visible in the topographic 


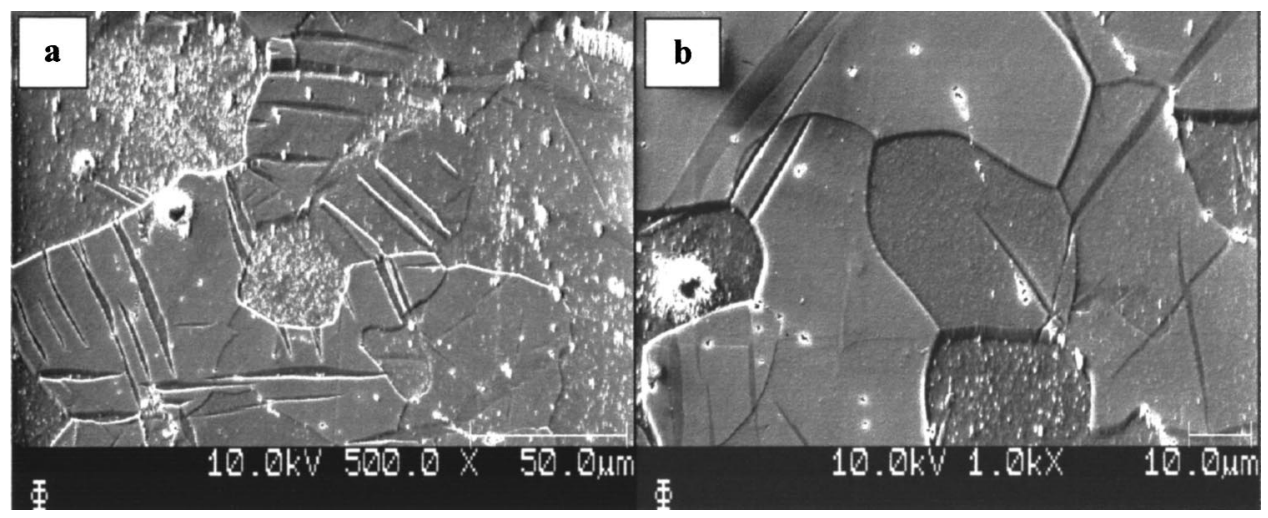

Figure 5. Scanning electron micrographs of different areas of a pure magnesium surface after polishing and $\mathrm{Ar}^{+}$ sputter etching. $7 \mu \mathrm{m}$ of the surface were removed by sputtering. maps, indicating that they also have a different rate of sputtering compared to the rest of the grains. Splinter et al. studied the initial oxidation of polycrystalline $\mathrm{Mg}$ by water vapor at room temperature using AES and X-ray photoelectron spectroscopy (XPS), and also observed that $\mathrm{Ar}^{+}$sputtering resulted in grain contrast. ${ }^{51}$ The grains exhibiting a dark secondary electron contrast were preferentially sputtered. All these grains showed nearly identical electron backscattering diffraction patterns, which were associated with a particular grain orientation having a surface normal very near the basal $\mathrm{Mg}(0001)$ pole. ${ }^{51}$ On the other hand, grains exhibiting bright secondary electron contrast were slightly raised with respect to the basal grains (lower sputter rate), and the diffraction patterns corresponded to less close-packed, higher index faces. ${ }^{51}$

Figure $6 \mathrm{~b}$ presents the potential distribution of the $\mathrm{Mg}$ surface. A strong potential contrast was observed between the grains, but this potential difference was not related to the difference in the corresponding topography (i.e., a difference in sputter rate). For example, grain B was sputtered to a greater depth than grain A, but they have similar potentials. The more noble potential grain located in the middle of the map in Fig. 6b was actually sputter etched to an intermediate depth. Both grain boundaries and intragranular defects also exhibit a different potential than the grains. It should be noted that the potential distribution shown in Fig. $6 \mathrm{~b}$ is not present on an as-polished sample; sputter etching is required to remove the polishing damage layer. This indicates that the oxide present on an aspolished sample might not be representative of the oxide that grows on a fresh metal surface prepared by other processes. This observation could be crucial in the initiation of corrosion processes on various passive surfaces, especially when defects such as scratches are preferential sites of attack. Splinter et al. indicated that the rate of oxidation of pure $\mathrm{Mg}$ surfaces is greater on grain faces that are less close-packed, with higher index crystallographic orientations. ${ }^{51}$ So the sputter etching rate and oxidation rates are dependent on the orientation and packing density of grains. However, there is no direct correlation between the measured Volta potential difference and the sputter etching rate. Although such a correlation between the measured Volta potential difference and packing density should exist in vacuum, the presence of the surface oxide indicates that the potential measured on an oxide-covered sample does not reflect the properties of a metallic substrate. The electrochemical and corrosion behavior of a surface in a passive state is given by the oxideelectrolyte interface and the relation between oxide structure changes and resulting electronic behavior are essential. The Volta potential difference measured by SKPFM is apparently related to subtle effects such as oxide structure changes or defect nature of this oxide, which is evidence of the detection power of the SKPFM technique.

Influence of various factors on the potential measured by the SKPFM.-In this work, most Volta potential difference measurements were performed with a tip-sample distance of $100 \mathrm{~nm}$. As mentioned in the introduction, according to theoretical considerations, the measured potential should not be constant below $100 \mathrm{~nm}$ due to the influence of image or dipole charges at the electrode surface. To investigate this, the influence on the measured potential of the dipoles in the interphase region was studied as a function of the vertical tip-sample distance. Besides the surface composition or oxide structure, other parameters such as adsorbed species at the electrode surface or any discharge of the electrode after emersion might also influence the measured potential.

Figure 7 shows the effect of tip-sample separation on the measured potential for pure $\mathrm{Al}$ directly after $30 \mathrm{~min}$ of immersion in DI water at OCP and 1 week later after storage in lab air. At separation distances greater than about $100 \mathrm{~nm}$, the potential is similar for the two cases, and independent of distance. This distance dependence of the potential with a constant domain above $100 \mathrm{~nm}$ is in good agreement with the literature. ${ }^{41,42}$ It should be mentioned that this distance between the tip and the sample is not an absolute value because, during the tapping mode scan, the tip is already at a few tens of nanometers from the surface. In any case, it seems that above 100 $\mathrm{nm}$ the measured potential is constant and can be assumed to be the Volta potential difference. However, close to the surface, the measured potential changes with tip-sample separation, and the trend is different at the two times. Adsorption phenomena might be responsible for this difference. Indeed, after 1 week of storage in air, the surface might dehydrate, which could change the dipole structure.

The influence of the adsorbed layer on the potential/distance relationship varies considerably for different metals. Ni showed almost no distance dependence over the full range of separation distances, and was independent of the time in air, Fig. 8. This suggests the nickel oxide surface is very stable and is the reason why $\mathrm{Ni}$ was chosen as a reference for the Volta potential difference measurements.

In contrast, the oxide on $\mathrm{Fe}$ is very complex, as is the resulting behavior. The potential is shown in Fig. 9 as a function of the tip-sample distance for pure Fe after $30 \mathrm{~min}$ of immersion in DI water at the OCP. Figure 9a corresponds to the potential of a sample that was dried in air at room temperature (RT) after polishing, and Fig. $9 \mathrm{~b}$ corresponds to the potential of a sample that was dried with forced warm air after polishing. Both samples were allowed to dry at RT after the $30 \mathrm{~min}$ immersion in water. The measured potential of the sample dried at RT after polishing is strongly dependent on the tip-sample distance, varying by almost $300 \mathrm{mV}$ between distances of $1 \mu \mathrm{m}$ and $10 \mathrm{~nm}$. The correlation of Volta potential with $\mathrm{OCP}^{2}$ suggests that the low potential on this air-dried sample indicates a more active surface. The potential of the electrode dried with warm air after polishing was much higher, which can be interpreted as being the result of a more passive surface, and did not depend strongly on tip-sample distance. The surface oxide might be dehydrated during the warm air drying so that it was more stable and protective and not modified by the subsequent immersion in DI water.

These results indicate that the potential measured by the SKPFM is strongly influenced by the adsorption of species at the electrode surface, especially at very short distances from the electrode surface. 

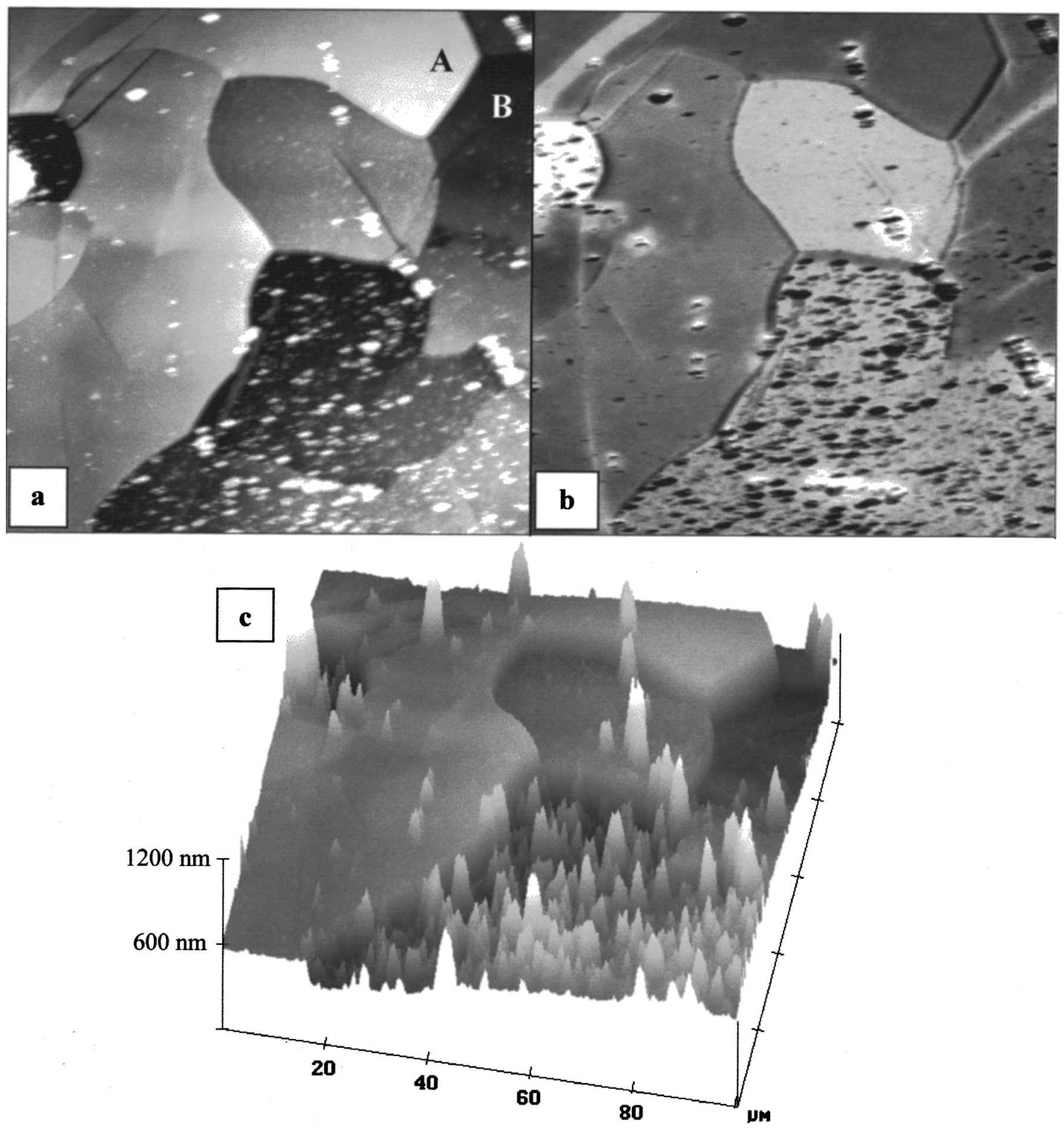

Figure 6. Region of Fig. 5 b: (a) $100 \times 100 \mu \mathrm{m}$ 2D AFM topographic image with a gray scale range of $800 \mathrm{~nm}$. (b) Volta potential difference distribution of the same area, with a gray scale range of $0.5 \mathrm{~V}$. (c) $100 \mu \mathrm{m} \times 100 \mu \mathrm{m} \times 600 \mathrm{~nm}$ 3D AFM topographic image

It is now important to understand the influence of different types of charges present in the surface region (including metal-oxide interface, oxide, oxide-adsorbed solution interface) on the Volta potential difference measured at a tip sample distance of $100 \mathrm{~nm}$. In the following, adsorption of different types of ions on the surface and the potential shift observed are presented as the contribution of the oxide/adsorbed-solution/air interface.

Potentials measured by SKPFM on a number of pure metal samples after exposure to DI water or $0.5 \mathrm{M} \mathrm{NaCl}$ were found to be linearly related to the OCP measured in solution before the samples were removed. ${ }^{2}$ Figure 10 shows this calibration curve with added values for potentials of $\mathrm{Ni}$ and Pt electrodes measured in air after 30 min immersion in $0.1 \mathrm{M} \mathrm{Na}_{2} \mathrm{SO}_{4}$ at open circuit. As was the case for samples exposed to chloride solution, both the OCP in sulfate solution and the Volta potential difference in air were shifted in the active direction by around $150 \mathrm{mV}$ relative to the values measured in and following DI water exposure. This suggests that adsorption of 


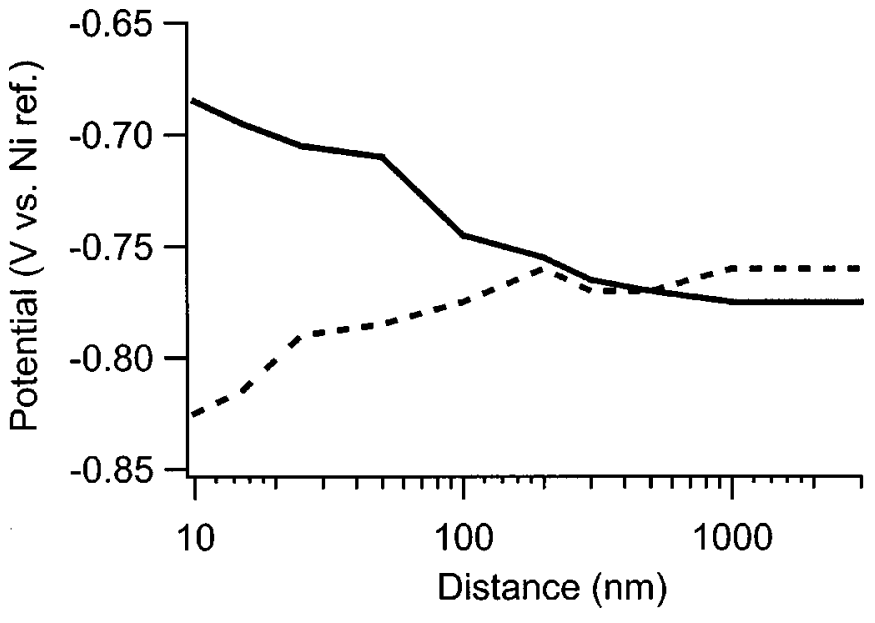

Figure 7. Potential measured as a function of tip-sample distance for pure Al after $30 \mathrm{~min}$ at OCP. (-) directly after removal from DI water and $(---), 1$ week later.

charged species at the electrode surface in chloride or in sulfate changed the dipole structure in the double layer and influenced the measured potential by the same value.

A second aspect is how charge accumulation within the oxide or at the oxide/metal interface influences the Volta potential difference measured at a tip-sample distance of $100 \mathrm{~nm}$, which is the common distance used for the SKPFM measurements. These experiments were performed by applying a cathodic polarization to the sample and emersing (withdrawing) the electrode under applied potential.

Figure 11 shows the potential evolution for a $\mathrm{Ni}$ sample after polarization in $0.1 \mathrm{M} \mathrm{Na}_{2} \mathrm{SO}_{4}$ at a potential $1 \mathrm{~V}$ below the OCP. Both the Volta potential difference measured in air in the SKPFM after emersion under potential control and the OCP of the second electrode in the electrolyte are shown, but the time scales for the two measurements are different. The potential in solution is given $v s$. the OCP measured for the Ni electrode prior to the polarization, which was $-740 \mathrm{mV} v s$. mercurous sulfate electrode (MSE) after $1 \mathrm{~min}$ immersion in the $\mathrm{Na}_{2} \mathrm{SO}_{4}$ solution. The potential in solution, measured with a standard electrochemical system, recovered to the original OCP value within $300 \mathrm{~s}$ of release of the potential control. In contrast, the Volta potential difference measured in air after emersion of the sample under potential control slowly decayed over $5 \mathrm{~h}$. It eventually reached a value equal to that measured immediately

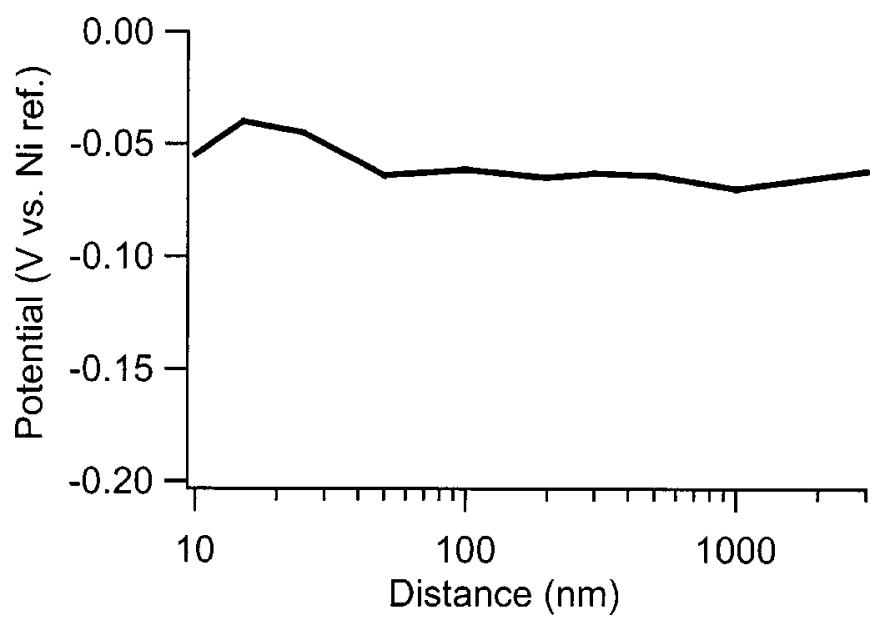

Figure 8. Potential measured as a function of tip-sample distance for pure $\mathrm{Ni}$ after 30 min immersion in DI water at $\mathrm{OCP}$.
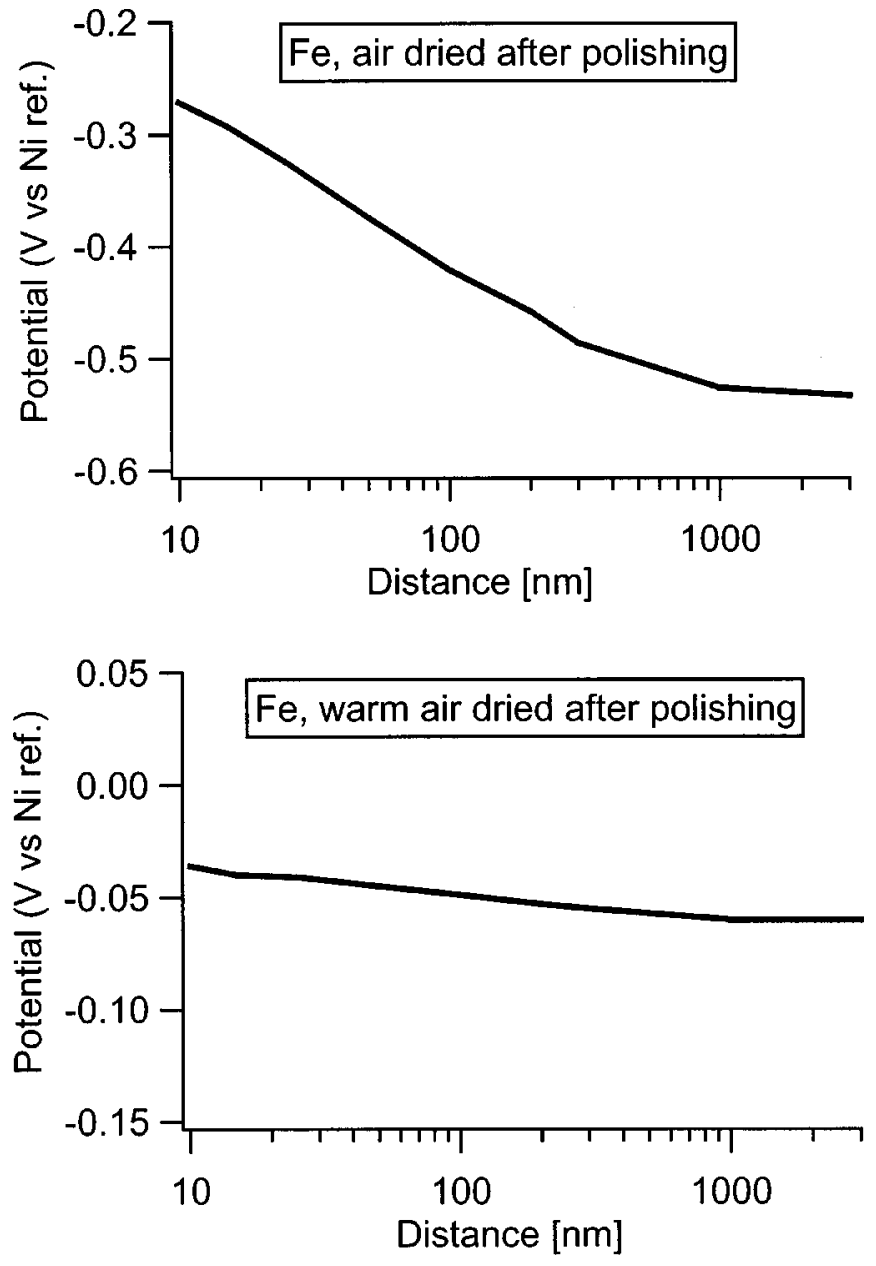

Figure 9. Potential measured as a function of tip-sample distance for pure Fe after 30 min immersion in DI water at OCP.

upon emersion from the $\mathrm{Na}_{2} \mathrm{SO}_{4}$ solution after 30 min immersion at open circuit. As mentioned previously (and shown in Fig. 10), this potential is $150 \mathrm{mV}$ lower than that measured after 30 min immersion at open circuit in DI water due to influence of the adsorbed ions on the charge distribution. It seems that the discharge of the surface of the sample exposed to air during $5 \mathrm{~h}$ following the emersion was

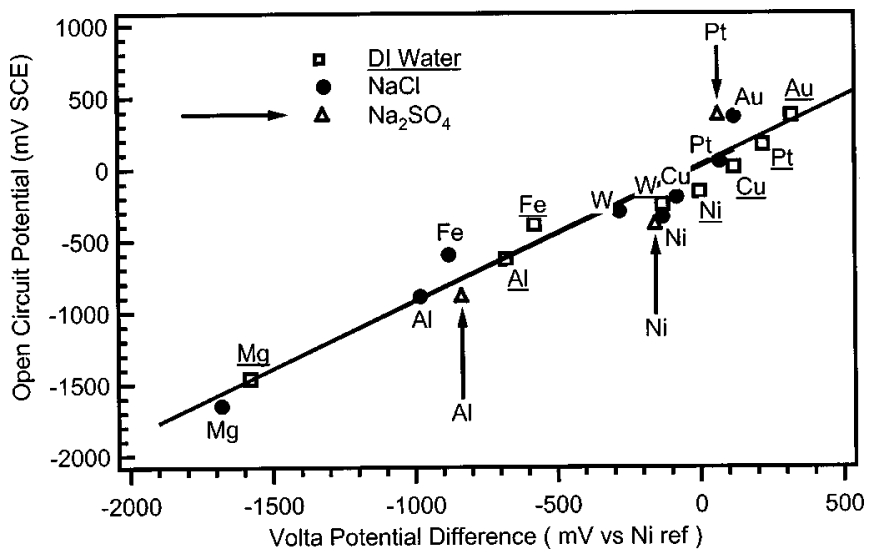

Figure 10. Comparison of the potential measured in air by SKPFM with open circuit measured in solution: in DI water ( $\square$ underlined, elemental symbols), in $0.5 \mathrm{M} \mathrm{NaCl}$ solution $(\bullet)$, and in $0.1 \mathrm{M} \mathrm{Na}_{2} \mathrm{SO}_{4^{2}}(\triangle$, indicated with an arrow). 


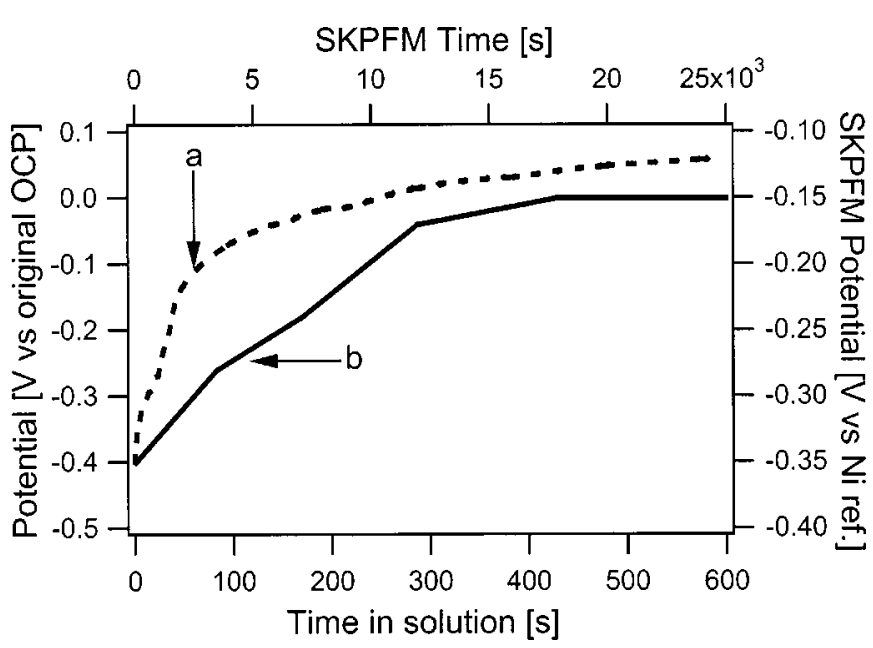

Figure 11. Pure $\mathrm{Ni}$ immersed $3 \mathrm{~min}$ in $0.1 \mathrm{M} \mathrm{Na}_{2} \mathrm{SO}_{4}$ at $-1500 \mathrm{mV} \mathrm{MSE}$ : (a) OCP of the electrode that remained in the electrolyte and (b) Volta potential difference measured in the SKPFM after emersion under potential control vs. Ni reference sample measured after DI water exposure at OCP.

the result of the discharge of the oxide film. The final stable Volta potential difference measured on the sample emersed under a controlled cathodic potential was identical to the value measured on the sample emersed from the same solution at open circuit. Indeed, it can be concluded that, after long times in air, only the sulfate ion adsorption influenced the surface charge distribution and consequently the SKPFM measurement. A second observation is that this influence of adsorption on the potential difference is independent of whether the sample was previously cathodically polarized or not.

For Pt, the OCP measured after 1 min immersion in the $\mathrm{Na}_{2} \mathrm{SO}_{4}$ solution was $-40 \mathrm{mV}$ MSE. Figure 12 shows the potential evolution for a Pt electrode after polarization in $0.1 \mathrm{M} \mathrm{Na}_{2} \mathrm{SO}_{4}$ at a potential 1 $\mathrm{V}$ below the OCP. As was shown in Fig. 11 for Ni, both the Volta potential difference measured in the SKPFM after emersion under potential control and the OCP of the second electrode in the electrolyte after releasing the potential control are given. The potential decay of Pt behaved similarly to what was observed on Ni, except that the decay was faster both during the SKPFM measurement in air as well as for the OCP measurement in solution. Faster discharge of the Pt surface is expected in this condition since the Pt surface

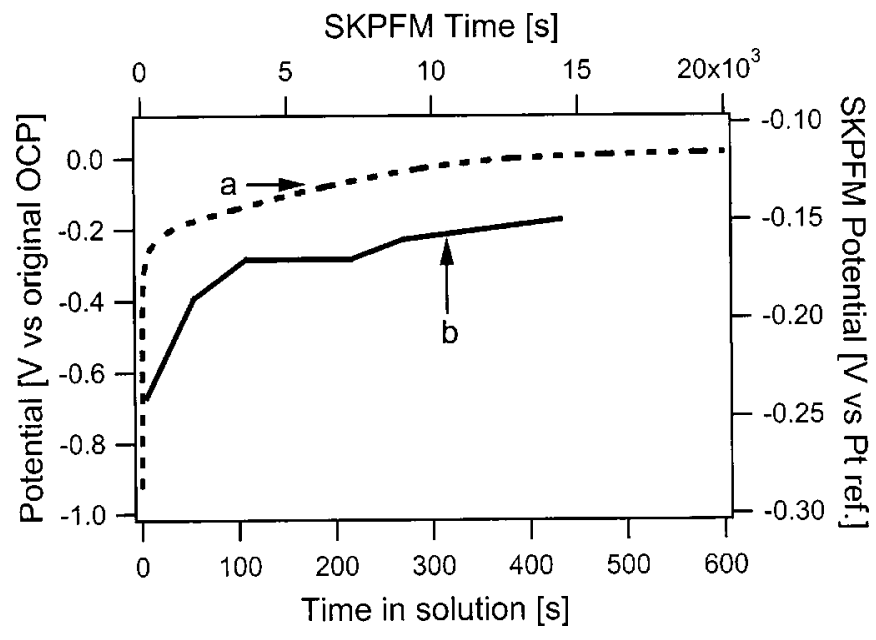

Figure 12. Pure Pt immersed $3 \mathrm{~min}$ in $0.1 \mathrm{M} \mathrm{Na}_{2} \mathrm{SO}_{4}$ at $-1000 \mathrm{mV}$ MSE: (a) OCP of the electrode that remained in the electrolyte and (b) Volta potential difference measured in the SKPFM after emersion under potential control $v s$. Pt reference sample measured after DI water exposure at OCP. does not form a thin oxide layer like nickel. As for $\mathrm{Ni}$, the Volta potential difference ended with a value equal to that measured immediately upon emersion from the $\mathrm{Na}_{2} \mathrm{SO}_{4}$ solution after $30 \mathrm{~min}$ immersion at open circuit, which again was $150 \mathrm{mV}$ lower than that measured after $30 \mathrm{~min}$ immersion at open circuit in DI water. Therefore, the discharge of the Pt surface also seemed to be only related to the discharge of the surface, and no influence of the cathodic polarization on the adsorption part could be detected.

The Volta potential difference measurements made by SKPFM on alloys following emersion from solution in this and previous studies ${ }^{1-4,31}$ have been performed within a few minutes following emersion. Figures 11 and 12 show that the total potential discharge of both $\mathrm{Pt}$ and $\mathrm{Ni}$ electrodes in air following emersion takes more than $1 \mathrm{~h}$ and is smaller in magnitude than the faster decay in OCP measured in solution after release of the potential control. This observation suggests that part of the potential decay in air is missed as a result of the few minutes required to set up the SKPFM measurement. Nonetheless, it can be concluded that the Volta potential difference measurements made during the first few minutes after emersion are a meaningful, if not exact, representation of the situation in solution. In corrosion studies, thick oxides that can accommodate considerable space charge are typically analyzed. Such surfaces discharge slower than noble metals like Pt, but the technique seems to be well suited for oxide-covered samples such as Al alloys.

These results show that the potential measured by the SKPFM at a tip-sample distance of $100 \mathrm{~nm}$ is influenced by both the surface charge distribution and the adsorbed species at the electrode surface. Even if the potential measured above $100 \mathrm{~nm}$ is constant, the Volta potential difference still contains a constant component related to the dipole contribution. One explanation is that adsorbed layer contains charge ions, permanent, and temporary induced dipoles. They have a different influence on the potential as a function of distance from the surface. The constant component added to the Volta potential difference might be related to the presence of charged $\mathrm{SO}_{4}^{2-}$ or $\mathrm{Cl}^{-}$ions and permanent dipoles on the surface.

It has been shown that for distances greater than $100 \mathrm{~nm}$ from the surface, the potential measured by SKPFM is constant, which corresponds to the conceptual definition of the Volta potential difference for a metal-solution interface. However, the separation between the influence of the surface dipoles and free charges contribution on the measured potential is theoretical and does not exist as such for a real solid-liquid interface. The influence of adsorbed dipoles dominates closer to the surface, but also influences the potential measured at distances equal to or greater than $100 \mathrm{~nm}$. Nonetheless, the overall nature of the potential measured by SKPFM justifies the description of it as the Volta potential difference.

\section{Conclusions}

The SKPFM technique provides a unique means of mapping the Volta potential difference distribution of a surface with submicrometer sensitivity. The results of this study develop a better understanding of the nature of the potential measured by the SKPFM and clarify how these potential measurements made in air can be representative of the situation in solution. The following observations were made.

1. The Volta potential difference contrast on the $\mathrm{Al}-\mathrm{Cu}-\mathrm{Mg}-$ containing particles in AA2024-T3 was reversed after sputter etching away 2-3 nm of the oxide film, suggesting a variation in the nature of the surface oxide when the outer part is removed. It is most probably electronic properties that change, because the composition does not significantly change. The susceptibility to corrosion of these particles also increased upon light sputtering according to the measured active nature in this case.

2. Light scratching of the 2024 surface by rastering with the AFM tip in contact mode at low set point voltage in chloridedichromate-containing solution resulted in the development of a high-potential structure that corresponded to SEM features but did not correspond to topographic features or compositional differences. 
3. Sputter etching of $7 \mu \mathrm{m}$ of the surface of a pure magnesium sample revealed the microstructure of the metal. A different potential contrast between the different grains and defects was then detected in the SKPFM.

4. Volta potential difference measurements on the sputtered $\mathrm{Mg}$ sample were found to detect very fine differences in the structure of the oxide film, most probably electronic in nature.

5. The effect of tip sample distance on measured potential was found to be complicated and depended on the material studied and the time after emersion. Changes in adsorption of species as a function of surface treatment and air aging of the electrode surface was found to have a strong influence on the potential measured when the tip/sample separation was small (below $100 \mathrm{~nm}$ ).

6. Studies of emersed electrodes showed that the Volta potential difference measured by the SKPFM at $100 \mathrm{~nm}$ from the surface still contains a constant component related to the dipole charge contribution.

\section{Acknowledgments}

This work was supported by the Air Force Office of Scientific Research under contract no. F49620-96-1-0479. T. Moffat and M. Stratmann are gratefully acknowledged for interesting discussions.

The Ohio State University assisted in meeting the publication costs of this article.

\section{References}

1. P. Schmutz and G. S. Frankel, J. Electrochem. Soc., 145, 2295 (1998).

2. P. Schmutz and G. Frankel, J. Electrochem. Soc., 145, 2285 (1998).

3. P. Schmutz and G. S. Frankel, in Proceedings of the 8th International Conference on Passivity of Metals and Semiconductors, M. B. Ives, Editor, Jasper, Canada (1999).

4. P. Schmutz and G. S. Frankel, J. Electrochem. Soc., 146, 4461 (1999).

5. Y. Martin, D. Abraham, and H. Wickramasinghe, Appl. Phys. Lett., 52, 1103 (1988).

6. C. C. Williams, J. Slinkman, W. P. Hough, and H. Wichramasinghe, Appl. Phys. Lett., 53, 1662 (1989).

7. L. F. Chi, S. Jacobi, and H. Fuchs, Thin Solid Films, 284-285, 403 (1996).

8. M. Fujihira and H. Kawate, Thin Solid Films, 242, 163 (1994).

9. M. Fujihira, M. Sakomura, D. Aoki, and A. Koike, Thin Solid Films, 273, 168 (1996).

10. A. Henning, J. S. T. Hochwitz, J. Never, S. Hoffmann, P. Kaszuba, and C. Daghlian, J. Appl. Phys., 77, 1888 (1995).

11. M. Yasutake, D. Aoki, and M. Fujihira, Thin Solid Films, 273, 279 (1996).

12. H. Yokoyama and T. Inoue, Thin Solid Films, 242, 33 (1994).

13. T. Yamamoto and S. Omika, in IEEE International Symposium on Applications of Ferroelectrics, pp. 411-414, IEEE, Montreaux, Switzerland (1998).

14. B. D. Huey, D. Lisjak, and D. A. Bonnel, J. Am. Ceram. Soc., 82, 1941 (1999).

15. H. O. Jacobs and A. Stemmer, Surf. Interface Anal., 27, 361 (1999).

16. H. K. Shin, T. Inoue, Y. S. Kwon, and H. Yokoyama, Synth. Met., 103, 1579 (1999).
17. R. Aveyard and D. A. Haydon, An Introduction of Surface Chemistry, Cambridge University Press, Cambridge (1973).

18. J. Hoelzl and F. K. Schulte, in Solid Surface Physics, Vol. 85, G. Hoehler, Editor, pp. 1-150, Springer-Verlag, Berlin, (1979).

19. N. Kizhakevariam, I. Villegas, and M. J. Weaver, Surf. Sci., 336, 37 (1995).

20. S. Trasatti, in NATO ASI Series, Vol. 179, A. F. Silva, Editor, Reidel, Dordrecht (1986).

21. S. Trasatti, Surf. Sci., 335, 1 (1995).

22. M. Stratmann and H. Streckel, Corros. Sci., 30, 681 (1990).

23. S. Yee, R. A. Oriani, and M. Stratmann, J. Electrochem. Soc., 138, 55 (1991).

24. M. Stratmann, K. T. Kim, and H. Streckel, Z. Metallkd., 81, 715 (1990).

25. M. Stratmann and H. Streckel, Ber. Bunsen-Ges. Phys. Chem., 92, 1244 (1988).

26. R. E. Lobnig, D. J. Siconolfi, J. Maisano, G. Grundmeier, H. Streckel, R. P. Frankenthal, M. Stratmann, and J. D. Sinclair, J. Electrochem. Soc., 143, 1175 (1996).

27. A. Leng, H. Streckel, and M. Stratmann, Corros. Sci., 41, 579 (1999).

28. A. Leng, H. Streckel, and M. Stratmann, Corros. Sci., 41, 547 (1999).

29. R. Feser and M. Stratmann, Werst. Korros., 42, 187 (1991).

30. M. Stratmann and H. Streckel, Werst. Korros., 43, 316 (1992).

31. V. Guillaumin, P. Schmutz, and G. S. Frankel, in Localized In-Situ Methods for Investigating Electrochemical Interfaces, S. R. Taylor, A. C. Hillier, and M. Seo, Editors, PV 99-28, p. 339, The Electrochemical Society Proceedings Series, Pennington, NJ (1999).

32. W. N. Hansen, C.-L. Wang, and T. W. Humpherys, J. Electroanal. Chem., 93, 87 (1978).

33. W. N. Hansen, C. L. Wang, and T. W. Humpherys, J. Electroanal. Chem., 90, 137 (1978)

34. D. M. Kolb and W. N. Hansen, Surf. Sci., 79, 205 (1979).

35. W. N. Hansen, Surf. Sci., 101, 109 (1980).

36. W. N. Hansen, D. M. Kolb, D. L. Rath, and R. Wille, J. Electroanal. Chem., 110, 369 (1980)

37. W. N. Hansen, J. Electroanal. Chem., 150, 133 (1983).

38. D. L. Rath and D. M. Kolb, Surf. Sci., 109, 641 (1981).

39. W. N. Hansen and D. M. Kolb, J. Electroanal. Chem., 100, 493 (1979).

40. G. J. Hansen and W. N. Hansen, J. Electroanal. Chem., 150, 193 (1983).

41. J. O. M. Bockris and A. K. N. Reddy, Modern Electrochemistry, Plenum Press, New York (1970).

42. J. O. M. Bockris and S. U. M. Khan, Surface Electrochemistry-A Molecular Level Approach, Plenum Press, New York (1993).

43. N. Sato, Electrochemistry at Metal and Semiconductor Electrodes, Elsevier, Amsterdam (1998)

44. E. M. Stuve, R. L. Borup, and D. E. Sauer, in The Application of Surface Analysis Methods to Environmental/Material Interactions, D. R. Baer, C. R. Clayton, and G. D. Davis Editors, PV 91-7, pp. 80-98, The Electrochemical Society Proceedings Series, Pennington, NJ (1991).

45. T. J. Warner, M. P. Schmidt, F. Sommer, and D. Bellot, Z. Metallk., 86, 494 (1995).

46. R. G. Buchheit, R. P. Grant, P. F. Hlava, B. McKenzie, and G. L. Zender, J. Electrochem. Soc., 144, 2621 (1997).

47. V. Guillaumin and G. Mankowski, Corros. Sci., 41, 421 (1999).

48. P. Schmutz and G. S. Frankel, J. Electrochem. Soc., To be submitted.

49. V. Guillaumin, P. Schmutz, and G. S. Frankel, J. Electrochem. Soc., To be submitted.

50. I. J. Polmear, in Light Alloys-Metallurgy of the Light Metals, 3rd ed., p. 232, Halsted Press, New York (1996)

51. S. J. Splinter, N. S. McIntyre, W. N. Lennard, K. Griffiths, and G. Palumbo, Surf. Sci., 292, 130 (1993). 